\title{
Economics of irrigation technology under conditions of spatially variable soils and nonuniform water distribution *
}

\author{
E. Feinerman ${ }^{1}$, E. Bresler ${ }^{2}$ and H. Achrish 1 \\ 1 The Hebrew University of Jerusalem, Department of Agricultural Economics and Management, Faculty of Agriculture, PO Box 12 , \\ Rehovot 76-100, Jerusalem; \\ 2 Institute of Soils and Water, ARO, The Volcany Center, Bet Dagan, Israel
}

(received 2 May 1988, accepted 13 June 1989)

Summary - This study focussed on the development and the application of an economic optimization model aimed at determining the optimal level of applied irrigation water under variable soil conditions and non-uniform water distribution, which maximizes the expected profits of a (risk-neutral) farmer. Subsequently, the model results have been used to evaluate and compare the profitability of 2 distinct irrigation methods for cotton, taking into account their uniformity of performance and their associated investment and operating costs.

The principal findings and conclusions can be summarized as follows: lower uniformity of water application is associated with a lower expected average yield (and obviously with lower expected profits) and, generally, with a higher optimal water level. The increase in the expected average yield under the more uniform irrigation method is higher when the uniformity of water infiltration is affected by the spatial variability of soil properties. This occurs in soils with a low water application rate, with low variability of hydraulic conductivity or both. In this case, the relative profitability of the more uniform (A), as compared to the less uniform irrigation (B), is increased.

Sensitivity analyses of water prices showed that an increase in water prices implied a decrease in optimal water level as well as in expected profits. It was found that the difference between the expected profits from the two irrigation methods are relatively unaffected by water prices.

The results are very sensitive to the form of yield function. Given a concave yield function, the level of average yield increases with the uniformity level of water infiltration. Two cotton yield functions were examined and compared. It was found, as expected, that the sensitivity of the average yield to non-uniformity in water infiltration is higher the more concave the function; and, in the case of a more concave function, the relative advantage of the more uniform (A) over the less uniform irrigation (B) is increased. Under the (more concave) yield function of Grimes et al. (1969), irrigation method A is more profitable than B whereas under the (almost linear) function of Saranga (1983), the opposite is the case.

spatially variable water - infiltration - economic optimization - evaluation of irrigation methods - sensitivity analysis

Résumé - Economie de la technologie d'irrigation en conditions de variabilité spatiale des sols et de répartition non-uniforme de l'eau. Cette étude est focalisée sur le développement et l'application d'un modèle d'optimisation économique visant à déterminer le niveau optimal d'application de l'eau en condition de sol variable et de répartition non-uniforme de l'eau, pour lequel le revenu prévu du cultivateur (risque neutre) est maximal. Les résultats du modèle ont été utilisés pour évaluer et comparer lintérêt de 2 méthodes distinctes d'irrigation du cotonnier, tenant compte de l'uniformité de leur performance, de l'investissement et du coût opératoire.

Les résultats et conclusions peuvent se résumer comme suit : une diminution de l'uniformité d'application de l'eau a pour effet un amoindrissement du rendement moyen espéré (et évidemment des revenus), et, en général, une augmentation de la quantité d'eau optimale. L'augmentation du rendement moyen espéré sous méthode d'irrigation plus uniforme est supérieure quand l'uniformité de l'infiltration de l'eau est affectée par la variabilité spatiale des propriétés du sol. Cela se produit dans les sols ayant une conductivité hydraulique basse (etlou faiblement variable). Dans ce

\footnotetext{
- Contribution presented at the Franco-Israeli Symposium on Irrigation Scheduling in October 1987.
} 
cas, l'intérêt relatif d'une irrigation plus uniforme $(A)$ est plus important que dans le cas de moindre uniformité du sol (B).

Des analyses de la sensibilité par rapport au prix de l'eau ont montré qu'une augmentation des prix de l'eau implique une baisse de la quantité optimale et des revenus espérés. On a trouvé que la différence entre les revenus espérés des 2 méthodes d'irrigation n'est presque pas affectée par les prix de l'eau.

Les résultats sont très sensibles à la forme de la fonction de production. Pour une fonction de production concave donnée, le niveau moyen du rendement augmente avec l'uniformité de l'infiltration. Deux fonctions de production du cotonnier ont été examinées et comparées. On a trouvé, comme prévu, que plus la fonction de production est concave, plus le rendement moyen est sensible à la non-uniformité de linfiltration, et dans le cas d'une fonction plus concave, l'avantage relatif d'une irrigation plus uniforme $(A)$ sur celle moins uniforme $(B)$ augmente. Pour les fonctions (plus concaves) de Grimes et al. (1969), la méthode d'irrigation $A$ est plus intéressante que $B$, tandis que pour la fonction (presque linéaire) de Saranga (1983), le contraire est vrai.

variabilité spatiale de l'infiltration d'eau - optimisation économique - évaluation de méthodes d'irrigation analyse de sensibilité

\section{INTRODUCTION}

In irrigated agriculture, the uneveness with which water infiltrates the root zone is determined mainly by the spatial variability (non-uniformity) of irrigation water application on the one hand and on the variability of hydrologic soil properties on the other (Russo \& Bresler, 1981; Warrick \& Gardner, 1983; Dagan \& Bresler, 1988). The yieid of a given crop is also spatially variable as it is assumed to be directly dependent on the spatially variable water infiltration (Bresler et al., 1981; Stern \& Bresler, 1983; Warrick \& Yates, 1987; Bresler \& Laufer, 1988).

Most economic studies on efficient water use are based on the assumption that soils are perfectly homogenous and that water is uniformly applied. In a few previous economic studies (e.g., Seginer, 1978; Feinerman et al., 1983), spatial variability of water application was considered. However, the spatial variation was regarded as deterministic. Feinerman et al. (1985) investigated the question of how economically efficient levels of applied water may vary as a function of yield random spatial variability, but they did not attempt to relate the variability to its origin and did not investigate its implication for the selection of the irrigation method.

The present study focusses on the development and application of an economic optimization model aimed at determining the optimal level of applied irrigation water, under variable soil conditions and non-uniform water distribution, which maximizes the expected profits of a risk-neutral decision maker (farmer). Subsequently, the model results are used to evaluate and compare the profitability of various irrigation methods, taking into account their uniformity performance and their associated investment and operational costs. The model was applied to cotton irrigated by 2 distinct irrigation methods. It should be noted that selecting uniformity performance as the main difference between the irrigation methods does not imply that there are no additional important differences, but that this selection has been made in order to focus on the importance of variability as an economic factor.

\section{GENERAL OUTLINE OF THE MODEL AND METHODOLOGY}

This section reports briefly the methodology and numerical approach for analyzing the effects of non-uniform irrigation on expected crop yield, optimum water application and expected profits. Most of the theoretical derivations have been omitted here, but can be found in Feinerman et al. $(1985,1986)$.

Consider an agricultural field with total area of $A$ hectares. Let the domain $A$ be partitioned into a set of equal subdomains $-\Delta \mathrm{A}_{i}$ with $x_{i}, i=1,2$, ..., $N$ being the field's coordinate vector at the centroid of the ith subdomain.

For any single point $x_{i}$, the infiltrated water depth can be related to average depth of applied water AW by:

$$
\text { IW }\left(x_{i}\right)=b\left(x_{i}\right) \text { AW }
$$

where $\operatorname{IW}\left(x_{i}\right)$ is the depth of water that has infiltrated in the soil at point $x_{i}$ and $\mathrm{b}\left(x_{i}\right)$ is a space-dependent spatial random function. This function is related to the variability of soil properties which determines how much water infiltrates into the soil and to the uniformity (variability) of water application. A common assumption is the existence of stationarity i.e., the random function (b) is completely characterized by its constant mean, $E\left[b\left(x_{i}\right)\right]=$ $E(b)$, and its 2-point covariance, $\operatorname{Cov}\left[b\left(x_{i}\right), b\left(x_{j}\right)\right]$, which does not depend separately on $x_{i}$ and $x_{j}$, but only on the difference vector $r_{i j}=\left|x_{i}-x_{j}\right|$ (e.g., Delhomme, 1978).

The yield per unit of field area, $Y\left(x_{i}\right)$, at point $x_{i}$, is related to the depth of water that infiltrates into the soil by: 


$$
Y\left(x_{i}\right)=f\left(I W\left(x_{i}\right)\right)=f\left(b\left(x_{i}\right) \text { AW }\right)
$$

where $f$ is the crop-water production function. The quantity of interest in the economic optimization problem is the space average yield over the field which can be approximated numerically by:

$$
\bar{Y}=\frac{1}{N} \sum_{i=1}^{N} Y\left(x_{i}\right)=\frac{1}{N} \sum_{i=1}^{N} f\left(b\left(x_{i}\right) A W\right)
$$

Obviously, $Y$ is a random variable, depending stochastically on the random functions $-\mathrm{b}\left(x_{i}\right), i$ $=1, \ldots, \mathrm{N}$, and deterministically on AW. The expectation of $Y$ is given numerically by:

$$
E(\bar{Y})=\frac{1}{N} \sum_{i=1}^{N} E\left[f\left(b\left(x_{i}\right) A W\right)\right]
$$

where $E$ is the expectation operator. Approximate relationships between $\mathrm{E}(\overline{\mathrm{Y}}), \mathrm{E}(b)=\bar{b}$ and the variance of $b$ can be found by employing a second-order Taylor expansion of $Y\left(x_{i}\right)$ about $f(\bar{b} A W)$

$$
\begin{aligned}
\bar{Y}=\frac{1}{N} \sum_{i=1}^{N} & {\left[f(\bar{b} A W)+\frac{\partial f(b A W)}{\partial(b A W) \mid b=\bar{b}} A W(b-\bar{b})\right.} \\
+ & \left.\frac{1}{2} \frac{\partial^{2} f(b A W)}{\partial(b A W)^{2} \mid b=\bar{b}} A^{2}(b-\bar{b})^{2}\right]
\end{aligned}
$$

and (since $\mathrm{E}(b-\bar{b})=0$ and $\mathrm{E}(b-\bar{b})^{2}=\mathrm{V}$ (b)); then,

$$
\begin{aligned}
E(\bar{Y})= & f(\bar{b} A W) \\
& +\frac{1}{2} \frac{\partial^{2} f(b \text { AW })}{\partial(b \text { AW })^{2} \mid b=\bar{b}} A W^{2} V(b)
\end{aligned}
$$

This means that as long as yield is a concave function of the quantity of infiltrated water [i.e., $\partial^{2}$ $\left.f(b A W) / \partial(b A W)^{2}<0\right]$, the expected average yield will be greater as the variance of $b$ decreases. Hence, the highest value of $E(\bar{Y})$ for any given level $A W$ will be achieved under uniform conditions, where $\mathrm{V}(b)=0$. As one can expect, $\mathrm{E}(\bar{Y})$ is an increasing function of $\bar{b}$, given that $f(\bar{b} \mathrm{AW})$ increases with infiltrated water.

To economically evaluate the optimal level of the decision variable AW, a profit function ( unit area) is selected as:

$$
\pi=P_{Y} \bar{Y}-P_{A W} A W
$$

where $P_{Y}$ is the income net of non-water variable costs per unit of yield $(\$ / \mathrm{kg})$ and $\mathrm{P}_{\mathrm{AW}}$ is the price of irrigation water $\left(\$ / \mathrm{m}^{3} \mathrm{H}_{2} \mathrm{O}\right)$.

The optimization problem of a profit maximizer decision maker is given by:

$$
{ }_{A W}^{\operatorname{MAX}} E(\pi)={ }_{A W}^{\operatorname{MAX}}\left\{P_{Y} E(\bar{Y})-P_{A W} A W\right\}
$$

The first-order condition for an optimum is:

$$
\frac{\partial E \overline{(Y)}}{\partial A W}=P_{A W} / P_{Y}
$$

When this condition is satisfied, water application is optimal since the field-wide expected addition to yield per added increment of applied water is just equal to the ratio of the price of water to income net of non-water variable costs. Note that the second-order condition is that:

$\partial^{2} \mathrm{E}(\overline{\mathrm{Y}}) / \partial(\mathrm{AW})^{2}<0$, i.e., the yield function $f(b A W)$ should be concave.

Up to this point, we have not attempted to explicitly relate the uncertainty of $b$ to its origin, but will do so now. As mentioned, the nonuniformity of water infiltration is assumed to be related to: (a) variability in satured hydraulic conductivity (soil dependent); and (b) variability in water application (irrigation dependent). Let $\mathrm{R}\left(x_{i}\right)$ and $\mathrm{K}\left(x_{i}\right)$ be the rate of water application $(\mathrm{mm} / \mathrm{h})$ and the saturated hydraulic conductivity $(\mathrm{mm} / \mathrm{h})$ respectively at point $x_{i}$ (the centroid of the $i$ th subdomain). Following Walker (1979), and Russo \& Bresler (1981), it is assumed that $\mathrm{R}\left(x_{i}\right)$ and $\mathrm{K}\left(x_{i}\right)$ are both spatially random functions with the following properties: and

The random vectors $\underline{R}=\left[\mathrm{R}\left(x_{1}\right), \ldots, \mathrm{R}\left(x_{\mathrm{N}}\right)\right]$ $\mathrm{K}=\left[\mathrm{K}\left(x_{1}\right), \ldots, \mathrm{K}\left(x_{\mathrm{N}}\right)\right]$ are multivariate normal (MVN) with constant expectations:

$\mathrm{E}\left[\mathrm{R}\left(x_{i}\right)\right]=\overline{\mathrm{R}}$ and $\mathrm{E}\left[\mathrm{K}\left(x_{i}\right)\right]=\overline{\mathrm{K}}$ respectively, and constant point variances:

$\mathrm{V}\left[\mathrm{R}\left(x_{i}\right)\right]=\mathrm{s}^{2} \mathrm{R}$ and $\mathrm{V}\left[\mathrm{K}\left(x_{i}\right)\right]=s^{2}{ }_{\mathrm{K}}$ respectively for every $i=1, \ldots, N$.

For any two arbitrary points, $x_{i}$ and $x_{j}$, the covariances $\operatorname{Cov}\left[\mathrm{R}\left(x_{i}\right), \quad \mathrm{R}\left(x_{j}\right)\right]$ and $\operatorname{Cov}\left[\mathrm{K}\left(x_{i}\right), \mathrm{K}\left(x_{j}\right)\right]$ are given by $s^{2}{ }_{\mathrm{R}} \exp \left(-\mathrm{r}_{i j} / \mathrm{I}_{\mathrm{R}}\right)$ and $s{ }^{2}{ }_{K} \exp \left(-r_{i j} / I_{K}\right)$, respectively, where $I_{R}$ and $I_{K}$ are respectively the linear integral scales (e.g., Feinerman et al. 1985) of $R$ and $K$.

Given $\mathrm{R}\left(x_{i}\right)$ and $\mathrm{K}\left(x_{i}\right)$, the rate $q\left(x_{i}\right)$ of infiltrated water at point $x_{i}$, can be calculated (Dagan \& Bresler, 1979) from:

$$
q\left(x_{i}\right)=\quad \begin{aligned}
& \mathrm{K}\left(x_{i}\right) \text { if } \mathrm{R}\left(x_{i}\right)>\mathrm{K}\left(x_{i}\right) \\
& \mathrm{R}\left(x_{i}\right) \text { if } \mathrm{R}\left(x_{i}\right) \leq \mathrm{K}\left(x_{i}\right)
\end{aligned}
$$

i.e., $q\left(x_{i}\right)=\operatorname{MIN}\left[\mathrm{K}\left(x_{i}\right), \mathrm{R}\left(x_{i}\right)\right]$.

The values of AW, $b\left(x_{i}\right)$ and IW $\left(x_{i}\right)$ during the irrigation season are given respectively by:

$$
\begin{aligned}
& \mathrm{AW}=\overline{\mathrm{R} T} \\
& b\left(x_{i}\right)=q\left(x_{i}\right) / \overline{\mathrm{R}} \\
& \mathrm{IW}\left(x_{i}\right)=q\left(x_{i}\right) \mathrm{T}=b\left(x_{i}\right) \overline{\mathrm{R}} \mathrm{T}
\end{aligned}
$$

where $T$ is the duration of the irrigation season and $\bar{R}$ is defined by $\bar{R}=1 / T \int_{0}^{T} R(t) d t$. 
The numerical approach used to calculate the optimal quantity of applied water (i.e., the value of AW which maximizes eq. 7) - for a given crop, soil properties and irrigation system - is comprised of the following stages:

Divide the field into a regular grid with $\mathrm{N}$ nodes. Subsequently, by using a standard random number generator (e.g., IMSL'S "GGNSM" subroutine), the random vectors $\underline{R}=$ $\left[\mathrm{R}\left(x_{1}\right), \ldots, \mathrm{R}\left(\mathrm{x}_{\mathrm{N}}\right)\right]$ and $\mathrm{K}=\left[\mathrm{K}\left(x_{1}\right), \ldots, \mathrm{K}\left(x_{\mathrm{N}}\right)\right]$ are generated synthetically for the appropriate multivariate normal distributions with predetermined values of the parameters $\left(\overline{\mathrm{R}}, \mathrm{s}^{2}{ }_{\mathrm{H}}\right.$, $\left.I_{R}\right)$ and $\left(\bar{K}, s^{2}{ }_{K}, I_{K}\right)$.

Given the (randomly generated) vectors $\underline{R}$ and $\mathrm{K}$, and a predetermined level of $A W$, values of $q\left(x_{i}\right)$ (eq. 9 ), $b\left(x_{i}\right)$ (eq. 11) and IW $\left(x_{i}\right)$, (eq. 12 ), are calculated for every node $i=1, \ldots, N$. (as detailed below, the above 2 stages were repeated many times).

Given IW $\left(x_{i}\right)$ and the crop water production function $f(b A W)$, the values of $Y\left(x_{i}\right)$ (eq. 2) and of $\bar{Y}$ (eq. 3) are calculated. These calculations have been made for each repetition of stages 1 and 2. The expectation of the average yield, $E(\bar{Y})$ (eq. 4), is then numerically calculated.

Given the prices $P_{Y}$ and $P_{A W}$, the optimal quantity of applied irrigation water and, subsequently, the optimal expected profits, are calculated by repeating the above 3 stages for a series of values of $A W$ in the relevant range and choosing the one which maximizes the expected profits, $E(\pi)$ (eq. 7).

\section{ILLUSTRATIVE EXAMPLE}

The methodology described in the previous section can be used for any crop-soil-water system for which the required input data are available. For the present analysis we illustrate the results for cotton, irrigated by 2 distinct irrigation methods. Most of the assumed or collected data were taken from the M. Sc. thesis of Achrish (1987).

The basic parameters characterizing the multivariate normal distribution of $\mathrm{K}$ for the Rehovot region of Israel are assumed to be:

$\left(\bar{K}, \mathrm{~s}^{2}{ }_{\mathrm{K}}, \mathrm{l}_{\mathrm{K}}\right)=\left(12 \mathrm{~mm} / \mathrm{h} ; 25(\mathrm{~mm} / \mathrm{h})^{2} ; 20 \mathrm{~m}\right)$.

For $\bar{R}$ we assume 2 distinct irrigation methods: $A$ with $\left(\bar{R}, s^{2}{ }_{R}, I_{R}\right)=(2 ; 0.0625 ; 10)$ and $B$ with $\left(\overline{\mathrm{R}}, s^{2}{ }_{\mathrm{R}}, \mathrm{I}_{\mathrm{R}}\right)=(7.2,3.31,10)$.

The basic selected crop water (concave) production function is based on Grimes et al. (1969), and is given by:

$Y=\mid \begin{array}{r}\left(-266.4+10.72 \mathrm{IW}-0.079(\mathrm{IW})^{2}\right) Y_{\max } \text { if } \mathrm{IW} \leq 80 \mathrm{~cm} \\ 0.85 Y_{\max } \text { if IW } \geq 80 \mathrm{~cm}\end{array}$ where $\mathrm{Y}$ is lint yield $(\mathrm{kg} / \mathrm{ha})$ and $\mathrm{Y}_{\max }=$ $6000 \mathrm{~kg} / \mathrm{ha}$. Note that the production function for $A$ and $B$ irrigations may not be identical because of differences in irrigation schedulling. However, we assume here that identical schedule is applied for both irrigation methods so that under other identical conditions the production functions for seasonal water quantities are also identical. In Israel, total cotton yield is comprised of $1 / 3$ lint yield and $2 / 3$ seed yield. Since $Y$ in eq. 13 is lint yield, the (weighted) cotton price which was chosen for the optimization problem (eq. 7) is $P_{Y}=P_{1}+2 P_{2}$, where $P_{1}=1.44 \$ / k g$ is lint price and $P_{2}=0.175 \$ / \mathrm{kg}$ is seed price. The assumed basic price of the irrigation water is $\mathrm{P}_{\mathrm{AW}}=0.1 \$ / \mathrm{m}^{3} \mathrm{H}_{2} \mathrm{O}$.

Equation (9) can be divided into 2 distinct cases: case $a$ when the uniformity of water infiltration is not affected by the spatial variability of soil properties (but only by the distribution of the irrigation water) i.e., $\mathrm{K}\left(x_{i}\right)>\mathrm{R}\left(x_{i}\right)$ and hence, $q\left(x_{i}\right)=\mathrm{R}\left(x_{i}\right)$; and case $b$ when it is affected by soil properties (in addition to water distribution, of course).

The relationships between expected average cotton yield and average applied water under cases $a$ and $b$ are presented respectively in Figures $1 a$ and $1 b$ for both irrigation methods $A$ and $B$. Under conditions of completely uniform irrigation, i.e., $s^{2} \mathrm{R}=0$ for $A$ as well as for $B$, the functions $E(\bar{Y})$ for both irrigation methods coincide in case $a$, whereas in case $b, E(\bar{Y})$ for $A$ is higher than for $B$. In order to explain the difference, let $R^{A},\left(R^{B}\right)$, be the value of $\bar{R}$ for $A$, (for $B$ ), and let $G^{A},\left(G^{B}\right)$, represent the set of all the points in the field in which $K\left(x_{i}\right)<R^{A}=2$, $\left(\mathrm{K}\left(x_{i}\right)<\mathrm{RB}^{\mathrm{B}}=7.2\right)$. In addition, note that the expectation and the variance of $b\left(x_{i}\right)$ are given respectively by (see eq. 11) $\bar{b}=\bar{q} / \bar{R}$ and $s^{2}{ }_{b}=$ $s{ }^{2} \overline{\mathrm{R}}^{2}$ and remember that, for a given level of $A W$, the yield at each point of the field increases with $\bar{b}$ and decreases with $s^{2}{ }_{b}$ (see eq. 5). In case $a$, under uniform irrigation, $s^{2}{ }_{\mathrm{R}}=0$ and $q$ $\left(x_{i}\right)=R$ for every $i$. Hence, $\bar{b}=1$ (no runoff) and $s^{2}{ }_{b}=0$ under both $A$ and $B$ irrigation systems. In case $b$, however, the number of points included in $G^{A}$ is much smaller than in $G^{B}$ (since $R^{B}>R^{A}$ ). Therefore, under irrigation method $A, \bar{b}$ and $s^{2} b$ are (approximately) equal to 1 and 0 , respectively, for every point in the field, whereas under method $\mathrm{B}$, for every $x_{i}$ in $\mathrm{GA}, q\left(x_{i}\right)=\mathrm{K}\left(x_{i}\right)$; $s^{2}{ }_{q}=s^{2} \mathrm{~K}>0 ; \bar{q}=\mathrm{E}\left[\mathrm{K}\left(x_{i}\right) \mid \mathrm{K}\left(x_{i}\right)<\overline{\mathrm{R}}\right]<\overline{\mathrm{R}}$ and hence $b<1$ (runoff) and $s^{2}{ }_{b}>0$. This explains why in case $b, E(\bar{Y})$ under system $A$ is higher than under system $B$ for every level of $A W$.

Additional inspection of Figures $1 a$ and $1 b$ shows that when the distribution of the irrigation water is non-uniform, $E(\bar{Y})$ under $A$ is greater 

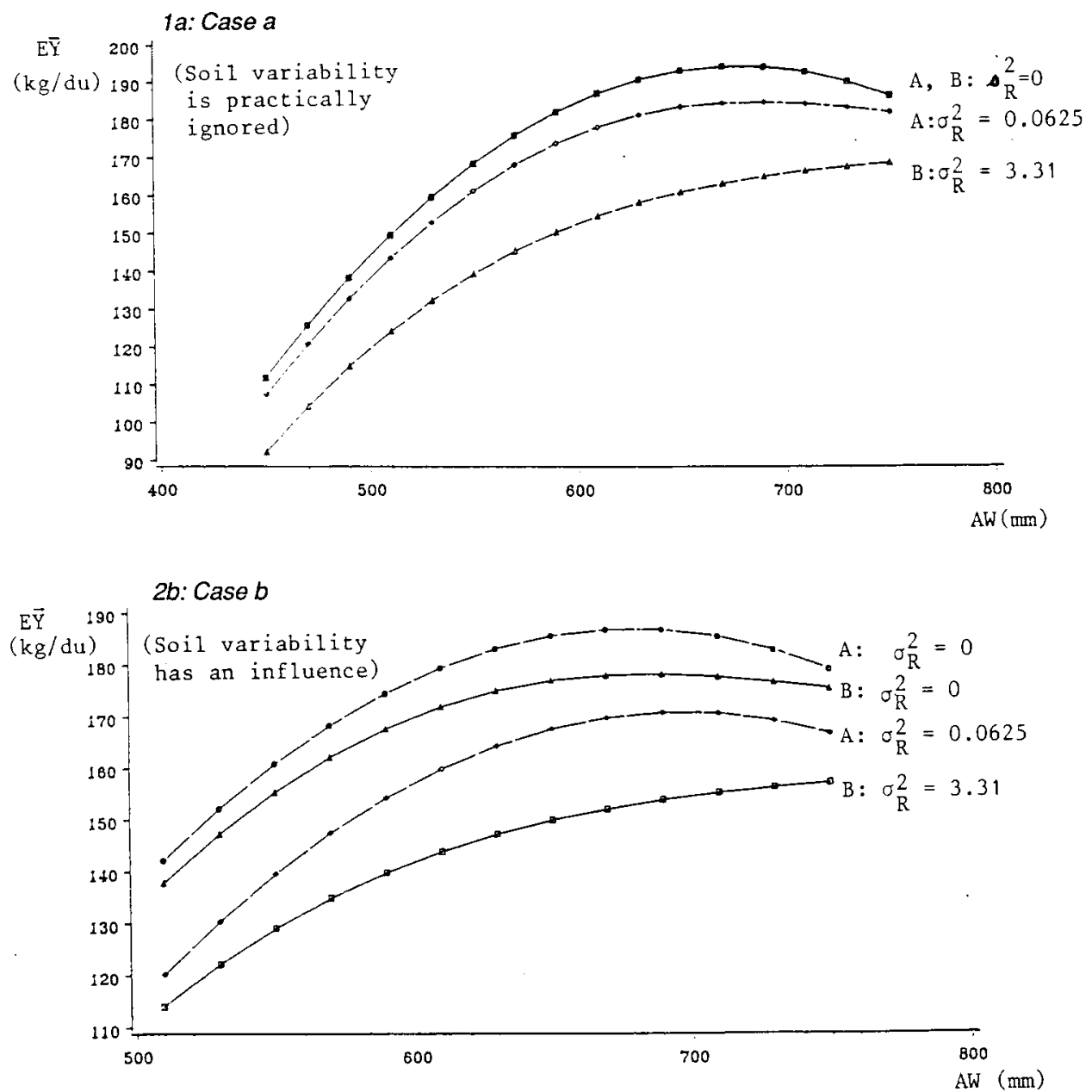

Fig. 1. Expected average yield $(E(\bar{Y}))$ as a function of average depth of applied water $(A W)$, for irrigation methods $A$ and $B$, under the basic values of the variance of water application $\left(\sigma^{2} R\right)$ and uniform water distribution $\left(s^{2} R=0\right)$.

than under $B$ for every level of AW. The reason can be easily explained in case $a$ (Fig. 1) where $q\left(x_{i}\right)=\mathrm{R}\left(x_{i}\right)$ for every $x_{i}, \bar{b}=1$ under both irrigation systems but the value of $\mathrm{s}^{2}{ }_{b}=\mathrm{s}^{2} \mathrm{R}_{\mathrm{R}} / \overline{\mathrm{R}}^{2}$ under system $B(0.064)$ is higher than under $A$ (0.016). The explanation in case $b$ is not so straightforward, but it can be carried along similar lines. Generally speaking, since the uniformity of water application under system $A$ is higher than the one under $B$, then the expected average yield under the first $(A)$ irrigation system is higher than under the latter $(B)$. The increase in the expected average yield under irrigation method $A$ is even higher when the uniformity of water infiltration is affected by the spatial variability of soil properties. This occurs in points of soils where saturated hydraulic conductivity is relatively low.

The optimal levels of $A W, E(\bar{Y})$ and $E(\pi)$, for both irrigation methods and under various levels of $S^{2} R$, are presented in Tables la and $\mathrm{lb}$ for cases $a$ and $b$ respectively.

Inspection of Table I suggests that under both cases and for both irrigation systems, higher uniformity of water applications (i.e., lower value of $s^{2}$ ) is associated with higher expected yield and higher expected profits, and also the optimal level of AW usually decreases as uniformity level increases. Comparison between systems $A$ and $B$ shows that as for our cotton, system $A$ is more efficient than $B$ and hence is potentially more profitable. The relative profitability of $A$, as compared to $B$, is higher under case $b$ (when the uniformity of water infiltration is affected by the spatial variability of hydraulic conductivity) than under case a.

The sensitivity of the optimal $A W, E(\bar{Y})$ and $E(\pi)$ to price of irrigation water showed (as expected) that raising water price implied a decrease in optimal water level as well as in expected profits. However, the increase in optimal $E(\pi)$ in $A$, as compared to $B$, is relatively unaffected by water prices (Fig. 2). The sensitivity of the results to the shape and the form of the crop-water production function was examined by adopting the following exponential yield function estimated by Saranga (1983):

$Y=156+526 /(1+14.4 \exp (-0.0137$ IW $))$

Using the production function (14), it was 
Table I. Optimal levels of applied water (AW), expected aAverage yield $(E(\bar{Y}))$ and expected profits $(E(\pi))$ for irrigation methods $A$ and $B$.

Case a (soil variability is pratically negligible)

Irrigation Method

\begin{tabular}{|c|c|c|c|c|c|c|}
\hline & \multicolumn{3}{|c|}{$A$} & \multicolumn{3}{|c|}{$B$} \\
\hline & \multirow[t]{2}{*}{$\begin{array}{c}\text { Uniform } \\
\text { application }\end{array}$} & \multicolumn{2}{|c|}{$\begin{array}{l}\text { Non-uniform } \\
\text { application }\end{array}$} & \multirow{3}{*}{$\begin{array}{c}\text { Uniform } \\
\text { application } \\
\mathrm{s}_{\mathrm{R}}^{2}=0\end{array}$} & \multicolumn{2}{|c|}{$\begin{array}{l}\text { Non-uniform } \\
\text { application }\end{array}$} \\
\hline & & Level 1 & Level 2 & & Level 1 & Level 2 \\
\hline & $\mathrm{s}^{2} \mathrm{R}=0$ & $S^{2}{ }_{R}=0.0625$ & $S^{2} R=0.16$ & & $\mathrm{~S}^{2} \mathrm{R}=1.87$ & $\mathrm{~s}^{2} \mathrm{R}=3.31$ \\
\hline & (1) & (2) & (3) & (4) & (5) & (6) \\
\hline $\mathrm{AW}\left(\mathrm{m}^{3} / \mathrm{ha}\right)$ & 6600 & 6600 & 6850 & 6600 & 6800 & 7250 \\
\hline$E \bar{Y}(\mathrm{~kg} / \mathrm{ha})$ & 1940 & 1840 & 1740 & 1940 & 1754 & 1674 \\
\hline$E \pi(\$ / h a)$ & 2810 & 2632 & 2430 & 2810 & 2460 & 2272 \\
\hline
\end{tabular}

Case b (soil variability has an influence)

\section{AW (m $\left.\mathrm{m}^{3} / \mathrm{ha}\right)$}

$E Y(\mathrm{~kg} / \mathrm{ha})$

$E \pi$ (\$/ha)
(1)

(2)

6600
1864
2676

(3)

6550
1774
2520

(4)

6800
1704
2371

(5)

6700

1587

2171
(6)

7200

1558 2070 found that the increase in the optimal levels of $E(\bar{Y})$ and $E(\pi)$ under system $A$, as compared to $B$, is relatively small for both cases $a$ and $b$. Comparison with the yield function of Grimes et al. (eq. 13) suggests, that the results are very sensitive to the form of the yield function. Obviously, the sensitivity of the average yield to non-uniformity of water infiltration is higher, as the production function is more concave (the "concavity degree" of Saranga's production function is much lower than that of Grimes et al.), and, in the case of more concave function, the relative advantage of system $A$ over $B$ is increased.

\section{IMPLICATIONS FOR THE SELECTION OF IRRIGATION TECHNOLOGY}

To compare the costs of systems $A$ and $B$, we assume that $A$ is comparable with permanent (solid set) drip and $B$ is comparable with movable sprinker. A levelled 40 ha cotton field is assumed and distinction between investment costs and operating variable costs is made. The detailed data and assumptions are given in Achrish (1987). The final main and relevant cash flows for systems A and B are summarized in Table II. It is assumed that the field has already been equipped with mains and submains and hence

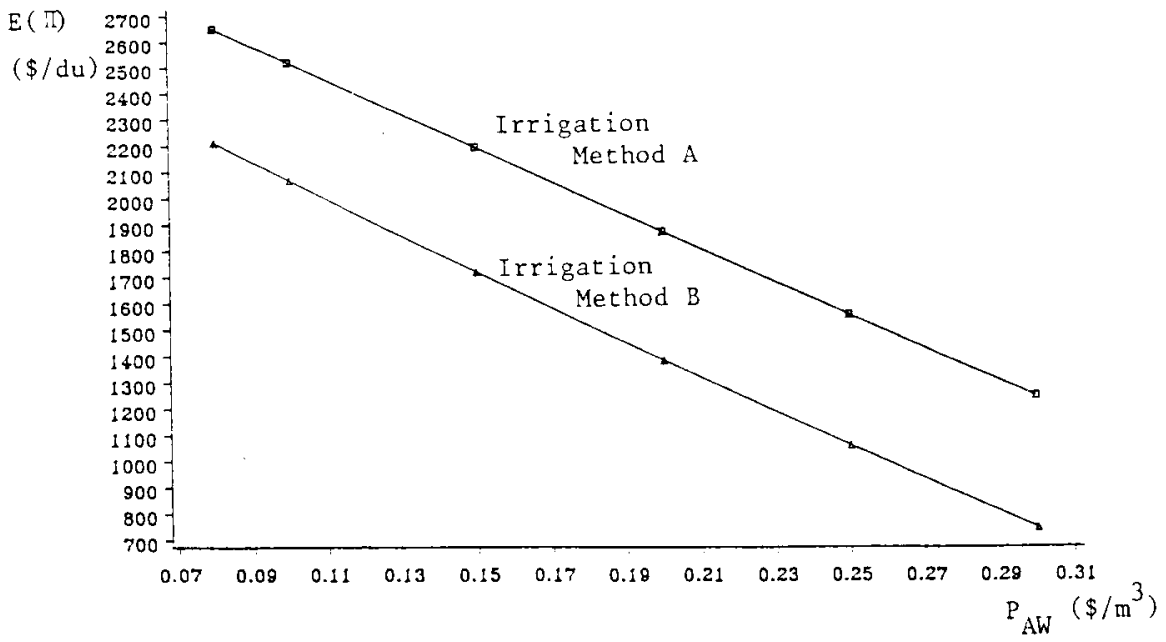

Fig. 2. Expected profits $(E(\pi))$ as function of various water prices $\left(P_{A W}\right)$ for both irrigation methods $(A$ and $B)$. 
Table II. Investment and operating costs $(\$ /$ ha) for irrigation methods $A$ and $B$ and different levels of real interest rate (r).

\begin{tabular}{|c|c|c|c|c|c|c|}
\hline \multicolumn{3}{|c|}{ Perha } & & \multicolumn{3}{|c|}{ Annual } \\
\hline & $A$ & $B$ & & $A$ & & $B$ \\
\hline & & & $r=5 \%$ & $r=10 \%$ & $r=5 \%$ & $r=10 \%$ \\
\hline Surface equipment & 1352 & 601 & 312 & 352 & 104 & 120 \\
\hline Filtering & 163 & - & 38 & 42 & - & - \\
\hline Investment costs & 1515 & 601 & 350 & 394 & 104 & 120 \\
\hline Operating costs & & & 223 & 223 & 293 & 293 \\
\hline Total & 1515 & 601 & 573 & 617 & 397 & 413 \\
\hline
\end{tabular}

the investment costs include only secondary surface equipment and laterals. The annual investment costs were calculated by using capital recovery factors at real interest rates of $r=5 \%$ and $r=10 \%$ on the total investment, with assumed $5 \mathrm{yr}$ of use for system $A$ equipment and $7 \mathrm{yr}$ for $\mathrm{B}$. The main components of the operating costs are labor, tractors and repairs.

The results of Table II, coupled with the results of Table I, can now be used to compare the profitability of both irrigation systems for cotton. (Note that we used cotton as an illustrative example. The results can be generalized.) For this, let $\Delta E(\pi)(\$ / h a)$ be the difference between the optimal expected profits of systems $A$ and $B$ and $\Delta C(\$ / h a)$ be the difference between their associated total annual investment and operating costs. The profitability advantage of $A$ over $B$ is measured by $\Delta R=\Delta E(\pi)-\Delta C$. Assuming the basic parameter values for $A$ and $B$, the values of $\Delta \mathrm{E}(\pi), \Delta \mathrm{C}$ and $\Delta \mathrm{R}$, for cases $a$ and $b$ and for both crop-yield production functions (eqs. 13 and 14) are presented in Table III.

The results of Table III suggests that the annual cost (i.e., investment and operation costs) of system $A$ is higher than that of $B$. Using the square yield function of Grimes et al., the increase in the expected profit for irrigation with system $A$ as compared to $B$ is higher than the increase in cost (especially under case $b$ ), and, thus, irrigating system $A$ is more profitable than the $B$ system. On the other hand, using the exponential yield function of Saranga (1983), which has much low concavity, the increase in the expected protit under irrigation system $A$ is lower than the increase in cost. In this case, system $A$ is less profitable than system $B$. These results demonstrate the substantial sensitivity of the results to the shape and form of the yield function and the importance of the identification and the estimation of the right yield function: 2 yield functions of the same crop yielded opposite conclusions.

\section{ACKNOWLEDGMENT}

This research has been financed in part by the United States Agency for International Development, in association with the US Departement of Agriculture, Office of International Cooperation and Development.

Table III. Difference between the optimal expected profits and the annual investment and operation costs of systems $A$ and $B$ (WE $\{$ and WC, respectively) and profitability advantage of $A$ over $B(W R)$.

Yield function

Grimes et al. (eq. 13)

Saranga (eq. 14)

Case a Case $\mathrm{b}$

Case a

Case b

$r=5 \% \quad r=10 \% \quad r=5 \% \quad r=10 \% \quad r=5 \% \quad r=10 \% \quad r=5 \% \quad r=10 \%$

\begin{tabular}{lllllrrrr}
$\Delta E(\pi)(\$ / h a)$ & 360 & 360 & 450 & 450 & 78 & 78 & 102 & 102 \\
$\Delta \mathrm{C}(")$ & 176 & 204 & 176 & 204 & 176 & 204 & 176 & 204 \\
$\Delta \mathrm{R}(")$ & 184 & 156 & 274 & 246 & -98 & -126 & -74 & -102 \\
\hline
\end{tabular}




\section{REFERENCES}

Achrish H. (1987) Economic optimization of irrigation under conditions of variable soil properties and nonuniform water distribution and its implication in the choice of the irrigation system. Unpublished M. Sc Thesis (in Hebrew), The Hebrew University of Jerusalem

Bresler E., Dasberg S., Russo D. \& Dagan G. (1981) Spatial variability of crop yield as stochastic soil process. Soil. Sci. Soc. Am. J. 45, 600-605

Bresler E. \& Laufer A. (1988) Statistical inference of soil properties and crop yields as spatial random functions. Soil. Sci. Soc. Am. J. 52, 1234-1244

Dagan G. \& Bresler E. (1979) Solute dispersion in saturated heterogeneous soil at field scale. I. Theory. Soil. Sci. Soc. Am. J. 43, 461-467

Dagan G. \& Bresler E. (1988) Variability of yield of an irrigated crop and its causes. III. Numerical simulation and field results. Water Resour. Res. 24, 395-401

Delhomme J.P. (1978) Kriging in the hydrosciences. Adv. Water Resources 1, 251-266

Feinerman E., Letey J. \& Vaux H.J. Jr. (1983) The economics of irrigation with non-uniform infiltration. Water Resour. Res. 19, 1410-1414

Feinerman E., Bresler E. \& Dagan G. (1985) Optimization of a spatially variable resource : an illustration for irrigated crops. Water Resour. Res. 21, $793-800$
Feinerman E., Bresler E. \& Dagan G. (1986) Statistical inference of spatial random functions. Water Resour. Res. 22, 935-942

Grimes D.W., Yamada H. \& Dickens W.L. (1969) Functions for cotton (Gossypium hirsutum L.) production from irrigation and nitrogen fertilization variables. I. Yield and evapotranspiration. Agron. J. 61, 769-773

Russo F. \& Bresler E. (1981) Effect of field variability in soil hydraulic properties on unsaturated water and salt flows. Soil Sci. Soc. Am. J. 45, 675-681

Saranga J. (1983) Cotton response to irrigation regime according to leaf water potential. Unpublished M. Sc. Thesis (in Hebrew), The Hebrew University of Jerusalem

Seginer I. (1978) A note on the economic significance of uniform water application. Irrig. Sci. 1, 19-25

Stern J. \& Bresler E. (1983) Non-uniform sprinkler irrigation and crop yield. Irrig. Sci. 4, 17-29

Walker W.R. (1979) Explicit sprinkler irrigation uniformity: efficiency model. J. Irrig. Drain. Div. 105, 129-136

Warrick A.W. \& Gardner (W.R.) 1983. Crop yield as affected by spatial variations of soil and irrigation. Water Resour. Res. 19, 181-186

Warrick A.W. \& Yates S.R. (1987) Crop yield as influenced by irrigation uniformity. Adv. Irrig. 4, 169180 